\title{
Maternal PLAC1 protein levels in early- and late-onset preeclampsia
}

\author{
Mujde Can Ibanoglu ${ }^{1}$, A. Seval Ozgu-Erdinc ${ }^{2}$, Dilek Uygur ${ }^{2}$ \\ ${ }^{1}$ Dr Nafiz Körez Sincan State Hospital, Ankara, Turkey \\ ${ }^{2}$ Dr Zekai Tahir Burak Women's Health Care, Education And Research Hospital, Ankara, Turkey
}

\begin{abstract}
Objectives: The objective of this study was to determine the maternal PLAC1 protein levels in early and late onset preeclampsia.

Material and methods: A total of 135 pregnant women were included in the study, of which 55 were at $<34$ weeks of gestation and 80 were at $\geq 34$ weeks of gestation, between June and November 2014 were recruited in this case control study.

Results: Analysis of maternal serum PLAC1 levels did not reveal any significant differences between early onset PE and controls $(p=0.422)$. However, late onset PE patients exhibited significantly elevated levels of PLAC1, in comparison with healthy controls $(p=0.026)$. The difference in PLAC1 levels between early onset PE and late onset PE was also significant $(p=0.001)$. Area under ROC curve of PLAC1 for early and late onset PE was 0.563 and 0.646 with $p$ values of 0.422 and 0.026 respectively. Area under ROC curve of PLAC1 in PE was 0.613 with $p$ value $=0.024$. The cutoff value for PLAC1 was $6.19 \mathrm{ng} / \mathrm{mL}$ with sensitivity: $56 \%(95 \% \mathrm{Cl} 44.1-67.3)$ and specificity: $63 \%$; $(95 \% \mathrm{Cl} 49.9-75.1)$ and diagnostic odds ratio: 2.2 (95\% Cl 1.1-4.4) ( $p$ value $=0.037$ ). The cutoff value for PLAC1 was $7.2 \mathrm{ng} / \mathrm{mL}$ with sensitivity: $43 \%$ (95\% Cl $31.5-54.6$ ) and specificity: $78 \%(95 \% \mathrm{Cl} 65.5-87.5)$ and diagnostic odds ratio: $2.69(95 \% \mathrm{Cl} 1.25-5.79)$ ( $\mathrm{p}$ value $=0.016$ )

Conclusion: In conclusion, the results of the current study showed that PLAC1 protein levels were significantly elevated in pregnant women with late onset PE in comparison with healthy control group.
\end{abstract}

Key words: pregnancy, maternal serum, PLAC1 protein, Preeclampsia

Ginekologia Polska 2018; 89, 3: 147-152

\section{INTRODUCTION}

Preeclampsia (PE) is a multi-system disorder and a major cause of maternal and fetal mortality or serious morbidity. However, most affected pregnancies end up at term with good maternal and fetal outcomes [1, 2]. Gestational hypertensive disorders cause complications in approximately 5-10\% of all pregnancies [3]. According to WHO2014 data, the second most common cause for maternal mortality is pregnancy-related hypertensive disorders (14\%) after hemorrhage [4]. In most women, the clinical features first come into view after 34 weeks of gestation (late onset PE). However, $10 \%$ of women develop PE before the $34^{\text {th }}$ week of gestation (early onset PE) [5]. 2003 and 2008 studies of $P E$ indicate that differences in its origins seem to result in phenotypic alterations of subtypes [5, 6]. Jackman SM, et al report that some proteins are involved in specific protein interactions with reference to a role at the maternal-fetal interface and are essential for normal placental development [7]. In Chang WL, et al there is evidence that suggests that Human placenta-specific protein-I (PLACI) is an important protein in placental development [8]. Jackman SM, et al also show that deficiency of placental PLAC1 protein results in hyperplastic placenta, and dysmorphic junctional zone [7].

The aim of our study was to determine the maternal PLAC1 protein levels in early- and late-onset PE pregnancies as there is potential for the protein levels to play a role in placental dysfunction.

\section{MATERIAL AND METHODS}

The protocol of this study was approved by the Ethics Committee of the Planning and Coordination Center at Dr. Zekai Tahir Burak Women's Health Care, Education and 
Research Hospital (\#18/2014) and informed consent was obtained from all participants before enrollment. The study followed the tenets of the Declaration of Helsinki [9].

Between June and November 2014, 135 pregnant women who had been admitted to the perinatology department of a tertiary referral hospital were enrolled in the study. PE was defined as elevated blood pressure in a previously normotensive woman after 20 weeks of gestation, either $\geq 140 / 90 \mathrm{mmHg}$ on two occasions at least four hours apart or $\geq 160 / 110 \mathrm{mmHg}$ within a short interval (minutes apart); and a proteinuria of $\geq 300 \mathrm{mg}$ in a 24-hour urine specimen [1]. In the absence of proteinuria, the diagnostic criteria consisted of new-onset hypertension together with thrombocytopenia, renal failure, poor liver function, pulmonary edema, or any visual symptoms [1]. Pregnancies with PE before 34 weeks of gestation were defined as early-onset preeclampsia, whereas pregnancies after 34 weeks were specified as late-onset PE. The control group was comprised of pregnant women with unremarkable pregnancy follow-ups. The exclusion criteria for the study and control groups were the presence of multiple pregnancies, systemic disease, a history of alcohol use or smoking and any chronic drug use.

On, admission, venous blood samples (10 cc) were collected in tubes containing ethylenediaminetetraacetic acid. The samples were centrifuged for $10 \mathrm{~min}$ and the plasmas were stored at $-80^{\circ} \mathrm{C}$ for subsequent assay. The maternal serum PLAC1 protein levels were determined using a sandwich enzyme-based technique in accordance with the manufacturer's instructions. (Cusabio Biotech Co., Stratech Scientific Limited. United Kingdom). Results were expressed as $\mathrm{ng} / \mathrm{mL}$.

The Statistical Package for Social Sciences (SPSS) for Windows 23.0 (SPSS Inc., Chicago, IL) was used for the analysis of the data. The normality of the variables was assessed by the Shapiro-Wilk test. Differences between the two independent groups were compared by Student's t and Mann-Whitney $U$ tests, where appropriate. The detection and false-positive rates of PLAC1 for the prediction of PE were estimated by using Receiver Operating Characteristic (ROC) curves analysis. A two-tailed $p$ value of less than 0.05 was considered to be statistically significant. Calculations for sensitivity, specificity, positive predictive value (PPV), negative predictive value (NPV), and positive likelihood ratio were carried out. Also checked were the negative likelihood ratio and diagnostic odds ratio with their associated $95 \% \mathrm{Cl}$.

\section{RESULTS}

Of the total of 135 pregnant women included in the study, 55 were at the $<34$-week gestation and 80 were at $\geq 34$-week gestation.

Table 1 illustrates the clinical picture of the patients at $\geq 34$ weeks of gestation. There were 30 patients with early onset PE and 25 in the control group. No significant differences were observed between the study group and control group in terms of their age, body mass index, gravida, gestational age, fetal biometric measurements, liver enzyme

Table 1. The clinical characteristics of the study participants at < 34 weeks of gestation

\begin{tabular}{|l|c|c|c|}
\hline & Early onset Preeclampsia $(\mathbf{n}=\mathbf{3 0})$ & Control $\mathbf{n}=\mathbf{2 5})$ & $\mathbf{p}$ \\
\hline Age (years) & $30.0 \pm 4.5$ & $29.7 \pm 6.0$ & 0.813 \\
\hline Body mass index [kg/m²] & $30 \pm 5$ & $28 \pm 4$ & 0.163 \\
\hline Gravida (number) & $2 \pm 1$ & $2 \pm 1$ & 0.145 \\
\hline Gestational age (weeks) & $31.0 \pm 2.3$ & $31.1 \pm 2.2$ & 0.833 \\
\hline Systolic blood pressure [mmHg] & $153.00 \pm 12.08$ & $113.60 \pm 6.38$ & $<0.001$ \\
\hline Diastolic blood pressure [mmHg] & $106.33 \pm 7.18$ & $68.80 \pm 7.81$ & $<0.001$ \\
\hline Birthweight [grams] & $1956.0 \pm 837.1$ & 0.002 \\
\hline BPD (weeks) & $30.90 \pm 2.55$ & $2682.0 \pm 768.3$ & 0.475 \\
\hline AC (weeks) & $30.57 \pm 2.57$ & $30.48 \pm 2.40$ & 0.738 \\
\hline FL (weeks) & $30.40 \pm 2.63$ & $30.44 \pm 2.38$ & 0.966 \\
\hline 24 hour urine protein [milligrams] & $828.17 \pm 460.30$ & $30.44 \pm 2.50$ & $<0.001$ \\
\hline Thrombocytes [/ $\mu$ l] & $228733.3 \pm 81062.7$ & - & 0.299 \\
\hline Alanine transaminase [IU/L] & $23.33 \pm 12.08$ & $251240.0 \pm 66979.6$ & 0.162 \\
\hline Aspartate transaminase [IU/L] & $16.23 \pm 10.94$ & $19.00 \pm 5.42$ & 0.165 \\
\hline Urea [mg/dL] & $20.57 \pm 7.73$ & $13.08 \pm 6.87$ & $15.16 \pm 5.58$ \\
\hline Creatinine [mg/dL] & $0.73 \pm 0.10$ & $0.62 \pm 0.11$ & 0.003 \\
\hline APGAR score at 5 minute & $7.90 \pm 2.23$ & $9.04 \pm 1.37$ & $<0.001$ \\
\hline P<0.05 & & 0.024 \\
\hline
\end{tabular}

$p<0.05$ indicates significant difference. Data are expressed as mean \pm standard deviation 
serum levels, and thrombocyte count $(p>0.05)$. With the exception of lower neonatal birth weight and a low Apgar score at minute $5(p<0.05)$, all of the preeclamptic group, namely systolic and diastolic blood pressure, serum urea and creatinine, and 24-hour urine protein, were elevated.

Table 2 illustrates the clinical picture of the pregnant women at the $\geq 34^{\text {th }}$ week of gestation. There were 45 patients with late onset PE and 35 in the control group. In patients with late onset $\mathrm{PE}$, higher gravidity, higher systolic and diastolic blood pressure, elevated serum urea and creatinine values, 24-hour urine protein, lower femur length measurement and a low Apgar score at minute 5 were detected $(p<0.05)$. No statistically significant differences were found between the study and control groups with regard to their age, body mass index, gestational age, abdominal circumference and bi-parietal diameter measurements, neonatal birth-weight, liver enzymes and thrombocyte levels $(p>0.05)$.

Analysis of maternal serum PLAC1 levels did not reveal any significant differences between early onset PE and the control group $(5.49 \pm 12.24 \mathrm{~g} / \mathrm{mL}$ vs. $4.96 \pm 1.79 \mathrm{ng} / \mathrm{mL}$, $p=0.422$ ). However, the late onset PE patients exhibited significantly elevated levels of $\mathrm{PIACl}$, in comparison with the healthy control group $(8.25 \pm 3.52 \mathrm{ng} / \mathrm{mlvs} .6 .83 \pm 4.19 \mathrm{ng} / \mathrm{mL}$, $\mathrm{P}=0.026)$. The difference in PLAC1 levels between early onset $\mathrm{PE}$ and late onset $\mathrm{PE}$ was also significant $(5.49+2.24 \mathrm{ng} / \mathrm{mL}$ vs. $8.25 \pm 3.52 \mathrm{ng} / \mathrm{mL}, \mathrm{p}=0.001$ ) (Tab. 3). No association was found between the severity of the disease and PLAC1 levels in either the early-onset PE or late-onset PE groups (Tab. 4).

The area under the ROC curve of the PLAC1 for earlyand late-onset PE was 0.563 and 0.646 with $p$ values of 0.422 and 0.026 respectively. The area under the ROC curve of the PLAC1 in PE was 0.613 with $p$ value $=0.024$. The cut-off value for PLAC1 was $6.19 \mathrm{ng} / \mathrm{mL}$ with sensitivity of $56 \%$ (95\% Cl 44.1-67.3), specificity of 63\%; (95\% Cl 49.9-75.1), and a diagnostic odds ratio of $2.2(95 \% \mathrm{Cl} 1.1-4.4)$ ( $\mathrm{p}$ value - 0.037). The cut-off value for PLAC1 was $7.2 \mathrm{ng} / \mathrm{mL}$ with sensitivity: $43 \%$ (95\% Cl 31.5-54.6) and specificity: $78 \%$ (95\% Cl 65.5-87.5) and a diagnostic odds ratio: $2.69(95 \% \mathrm{Cl}$ $1.25-5.79)(p$ value $=0.016)($ Tab. 5)

\section{Table 2. The clinical characteristics of the study participants at $\geq 34$ weeks of gestation}

\begin{tabular}{|l|c|c|c|}
\hline & Late onset Preeclampsia $(\mathbf{n}=\mathbf{4 5})$ & Control $\mathbf{( n = 3 5 )}$ & $\mathbf{p}$ \\
\hline Age (years) & $31.1 \pm 5.9$ & $28.2 \pm 5.5$ & 0.031 \\
\hline Body mass index [kg/m²] & $32 \pm 5$ & $31 \pm 4$ & 0.510 \\
\hline Gravida (number) & $3 \pm 2$ & $2 \pm 1$ & 0.034 \\
\hline Gestational age (weeks) & $37.4 \pm 1.5$ & $38.1 \pm 2.0$ & 0.218 \\
\hline Systolic blood pressure [mmHg] & $150.60 \pm 12.78$ & $114.57 \pm 8.17$ & $<0.001$ \\
\hline Diastolic blood pressure [mmHg] & $103.71 \pm 11.33$ & $72.91 \pm 982$ & $<0.001$ \\
\hline Birthweight [grams] & $3154.7 \pm 623.9$ & 0.957 \\
\hline BPD (weeks) & $37 \pm 2$ & $3202.9 \pm 442.9$ & 0.524 \\
\hline AC (weeks) & $37 \pm 2$ & $37 \pm 1$ & 0.941 \\
\hline FL (weeks) & $36 \pm 1$ & $37 \pm 2$ & 0.031 \\
\hline 24 hour urine protein [milligrams] & $773.04 \pm 963.13$ & $37 \pm 1$ & $<0.001$ \\
\hline Thrombocytes [/ $\mu$ l] & $235.000 \pm 61.000$ & $\mathrm{~N} / \mathrm{A}$ & 0.455 \\
\hline Alanine transaminase [IU/L] & $24 \pm 34$ & $254.000 \pm 69.000$ & 0.846 \\
\hline Aspartate transaminase [IU/L] & $24 \pm 71$ & $19 \pm 5$ & 0.630 \\
\hline Urea [mg/dL] & $20 \pm 6$ & $12 \pm 5$ & $<0.001$ \\
\hline Creatinine [mg/dL] & $0.71 \pm 0.11$ & $15 \pm 4$ & $<0.001$ \\
\hline APGAR score at 5 minute & $8.93 \pm 1.10$ & $9.49 \pm 0.56$ & 0.001 \\
\hline
\end{tabular}

Table 3. Comparison of PLAC 1 levels

\begin{tabular}{|l|c|c|c|}
\hline \multirow{2}{*}{ Control } & \multicolumn{2}{|c|}{ Maternal serum PLAC1 [ng/mL] } \\
\hline & Gestational age $<\mathbf{3 4}$ weeks & Gestational age $\geq \mathbf{3 4}$ weeks & $\mathbf{p}$ \\
\hline Preeclampsia & $4.96 \pm 1.79$ & $6.83 \pm 4.19$ & \\
\hline P & $5.49 \pm 2.24$ & $8.25 \pm 3.52$ & $0.001^{\text {a }}$ \\
\hline
\end{tabular}


Table 4. Impact of factors on PLAC1 levels

\begin{tabular}{|c|c|c|c|c|c|c|c|}
\hline & \multicolumn{6}{|c|}{ PLAC 1} \\
\hline & & \multicolumn{3}{|c|}{ Early onset PE } & \multicolumn{3}{|c|}{ Late onset PE } \\
\hline & & $n$ & Mean \pm SD & $\mathbf{p}^{*}$ & $n$ & Mean \pm SD & $\mathrm{p}^{*}$ \\
\hline \multirow{2}{*}{ Severity of disease } & MILD & 10 & $5.36 \pm 2.06$ & \multirow{2}{*}{0,948} & 20 & $8.17 \pm 3.85$ & \multirow{2}{*}{0.689} \\
\hline & SEVERE & 20 & $5.55 \pm 2.38$ & & 25 & $8.32 \pm 3.41$ & \\
\hline
\end{tabular}

SD - Standart deviation; * Mann-Whitney U Test

Table 5. Diagnostic performances of PLAC1

\begin{tabular}{|l|c|c|}
\hline & $\begin{array}{c}\text { PLAC1 } \\
\text { CUT-OFF 6.19 }\end{array}$ & $\begin{array}{c}\text { PLAC1 } \\
\text { CUT-OFF 7.2 }\end{array}$ \\
\hline Sensitivity (\%) and 95\% Cl & $56(44.1-67.28)$ & $42.67(31.48-54.6)$ \\
\hline Specificity (\%) and 95\% Cl & $63.33(49.85-75.11)$ & $78.33(65.46-87.52)$ \\
\hline Positive Likelihood Ratio and 95\% Cl & $1.53(1.04-2.25)$ & $1.97(1.14-3.41)$ \\
\hline Negative Likelihood Ratio and 95\% Cl & $0.70(0.53-0.91)$ & $0.73(0.60-0.90)$ \\
\hline Positive Predictive Value (\%) and 95\% Cl & $65.63(52.61-76.75)$ & $71.11(55.48-83.16)$ \\
\hline Negative Predictive Value $(\%)$ and $95 \% \mathrm{Cl}$ & $53.52(41.36-65.3)$ & $52.22(41.49-62.77)$ \\
\hline Diagnostic Odds Ratio and 95\% Cl & $2.2(1.1-4.4)$ & $2.69(1.255 .79)$ \\
\hline
\end{tabular}

\section{DISCUSSION}

The present study showed an increase in maternal serum PLAC1 protein levels in late onset PE compared with the control and the early-onset PE groups. However, no association was established between the severity of PE and PLAC1 levels in either the early- or late-onset groups.

Though many theories have been proposed, the etiology of PE remains unknown. Impaired placentation, oxidative stress, thrombocyte and thrombin activation are among the pathogenetic mechanisms of PE together with endothelial dysfunction, imbalance of angiogenesis and intravascular inflammation [10]. Valensise et al. and von Dadelszen et al. reported that the variety in the pathophysiology of these disorders results in the different presentations of the disease (early- and late-onset PE) [5, 6]. Vatten et al. reported that placental dysfunction constitutes the basis of early-onset $P E$, whereas the composition of other factors may play a role in the development of the late-onset of the disorder [11]. Fant et al. found that apoptotic changes within placental villus trophoblast and leakage from the damaged placental villus trophoblast due to hypoxia or oxidative stress were the causes of the increase in plasma proteins in preeclamptic women [12].

Cocchia et al. recently identified a placenta-specific gene on the Xq26 chromosome as the PLAC1 gene and it has been shown that the gene expression is observed from the beginning of pregnancy until the end in the human placenta $[13,14]$. The PLAC1 gene may facilitate trophoblastic interactions peculiar to the placental-uterine interface [13] and may constitute a marker of placental development [15]. PLAC1 mRNA expression is restricted to cells of trophoblastic lineage $[13,14,16]$. Detectable expressions of PLAC1 mRNA are not observed in adult or fetal tissues. However, recent studies demonstrated decreased levels in testis and cerebellum [17]. PLAC1 is localized in human placental syncytiotrophoblast $[16,18]$. These observations are indications of the PLAC1 polypeptide being a membrane-associated protein. Whether PLAC1 is localized extracellularly, intracellularly, or is, in fact, an integral membrane component that becomes internalized is still not clear from these studies. Human amniotic fluid (16-18-week gestation) and maternal serum (25-33 weeks) analysis show no identification of the soluble PLAC1 protein in these compartments. This suggests that the PLAC1 polypeptide does not circulate. However, it acts locally at the level of the trophoblast [12].

The restricted nature of PLAC1 expression suggests it might serve as a useful biomarker that is indicative of functional disruptions at the maternal-fetal interface. This explanation was supported by Concu et al. [15] in their study which demonstrated that PLAC1 mRNA can be found in maternal serum as early as the 8th week of gestation and during pregnancy. The half-life of circulating fetal DNA increases fourfold in patients with preeclampsia [19]. The occurrence of higher circulating concentrations of the PLAC1 protein, observed in preeclampsia, might be contributed by similar mechanisms. Kodama et al. demonstrated that cell-free mRNA levels of PLAC1 were eight times higher in preeclamptic patients compared with their control group [20]. In previous studies, PLAC1 gene expression was reported as higher in PE patients compared with results for control groups [21, 22]. Farina et al. showed that there is a decre- 
ased level of circulating PLAC1 mRNA in cases associated with the risk of abortion before the 20th week of gestation. This, however, is not applicable for pregnancies after the 20th week [23]. Subsequent studies reported high levels of circulating PLAC1 mRNA in preeclampsia. These were in direct relation to the severity of the disease [22]. $\mathrm{Ng}$ et al. suggested different ways to clarify the fluctuations in circulating PLAC1 mRNA with PE [24]. The first elevated apoptosis that occurs within the villous trophoblast during PE [25] may have a link to the increased release of trophoblast-specific mRNA's and the shedding of membrane particles into the maternal plasma [20]. PLAC1 mRNA concentrations are a function of PE severity and the time of onset. These concentrations are higher in early-onset PE than in late-onset $P E[22,26]$. This is the first study in the literature evaluating maternal serum PLAC1 protein levels in early- and late-onset PE. We found that late-onset PE was associated with higher levels of maternal serum PLAC1 protein. Our findings also revealed that serum PLAC 1 levels were notably higher in pregnant women with late-onset PE when compared with those with early-onset. However, PLAC1 protein levels were not influenced from the severity of the disease in PE groups. The cellular function of PLAC1 remains unknown. However, it is believed to be associated with the membrane, and it was linked to trophoblast differentiation [7, 18]. It is also a possibility that the higher levels of PLAC1 are related to an abnormal interaction between trophoblast and uterine tissues which induces a defective vascular remodeling of maternal spiral arteries leading to a non-invasion of trophoblast and placental insufficiency $[27,28]$.

After all, our study has some limitations. As a potential effect of gestational age, the PLAC1 may manifest changes during pregnancy. More comprehensive studies are needed to reach a better conclusion and to provide percentile ranks for the pregnancy weeks.

In conclusion, the results established by our study showed that PLAC1 protein levels were significantly elevated in pregnant women with late-onset PE compared with the healthy control group. Future studies are necessary to establish whether PLAC 1 protein levels may be used as a screening tool for late-onset PE.

\section{REFERENCES}

1. American College of Obstetricians and Gynecologists, Task Force on Hypertension in Pregnancy. Hypertension in pregnancy. Report of the American College of Obstetricians and Gynecologists'Task Force on Hypertension in Pregnancy. Obstet Gynecol. 2013; 122(5): 1122-1131, doi: 10.1097/01.AOG.0000437382.03963.88, indexed in Pubmed: 24150027.

2. Hutcheon JA, Lisonkova S, Joseph KS. Epidemiology of pre-eclampsia and the other hypertensive disorders of pregnancy. Best Pract Res Clin Obstet Gynaecol. 2011; 25(4): 391-403, doi: 10.1016/j.bpobgyn.2011.01.006, indexed in Pubmed: 21333604.

3. Cunningham FG, Leveno KJ, Bloom SL, Spong CY, Dashe JS, Hoffman BL, Casey BM, Sheffield JS. Hypertensive Disorders. In: Williams Obstetrics. 24th Edition. McGraw-Hill, New York 2014: 728-779.
4. Say L, Chou D, Gemmill A, et al. Global causes of maternal death: a WHO systematic analysis. Lancet Glob Health. 2014; 2(6): e323-e333, doi: 10.1016/S2214-109X(14)70227-X, indexed in Pubmed: 25103301.

5. Valensise H, Vasapollo B, Gagliardi G, et al. Early and late preeclampsia: two different maternal hemodynamic states in the latent phase of the disease. Hypertension. 2008; 52(5): 873-880, doi: 10.1161/HYPERTENSIONAHA.108.117358, indexed in Pubmed: 18824660.

6. von Dadelszen P, Magee LA, Roberts JM. Subclassification of preeclampsia. Hypertens Pregnancy. 2003; 22(2): 143-148, doi: 10.1081/PRG120021060, indexed in Pubmed: 12908998.

7. Jackman $\mathrm{SM}$, Kong X, Fant ME, et al. Plac1 (placenta-specific 1 ) is essential for normal placental and embryonic development. Mol Reprod Dev. 2012; 79(8): 564-572, doi: 10.1002/mrd.22062, indexed in Pubmed: 22729990.

8. Chang WL, Yang $\mathrm{Q}$, Zhang $\mathrm{H}$, et al. Role of placenta-specific protein 1 in trophoblast invasion and migration. Reproduction. 2014; 148(4): 343-352, doi: 10.1530/REP-14-0052, indexed in Pubmed: 24989904.

9. World Medical Association. World Medical Association Declaration of Helsinki: ethical principles for medical research involving human subjects. JAMA. 2013;310(20): 2191-2194, doi: 10.1001/jama.2013.281053, indexed in Pubmed: 24141714.

10. Chaiworapongsa T, Chaemsaithong P, Yeo L, et al. Pre-eclampsia part 1: current understanding of its pathophysiology. Nat Rev Nephrol. 2014 10(8): 466-480, doi: 10.1038/nrneph.2014.102, indexed in Pubmed: 25003615.

11. Vatten LJ, Skjaerven R. Is pre-eclampsia more than one disease? BJOG. 2004; 111(4): 298-302, doi: 10.1111/j.1471-0528.2004.00071.x, indexed in Pubmed: 15008762.

12. Fant M, Farina A, Nagaraja R, et al. PLAC1 (Placenta-specific 1): a novel, $\mathrm{X}$-linked gene with roles in reproductive and cancer biology. Prenat Diagn. 2010; 30(6): 497-502, doi: 10.1002/pd.2506, indexed in Pubmed: 20509147.

13. Cocchia $M$, Huber $R$, Pantano $S$, et al. PLAC1, an Xq26 gene with placenta-specific expression. Genomics. 2000; 68(3): 305-312, doi: 10.1006/geno.2000.6302, indexed in Pubmed: 10995572.

14. Fant $M$, Weisoly DL, Cocchia M, et al. PLAC1, a trophoblast-specific gene, is expressed throughout pregnancy in the human placenta and modulated by keratinocyte growth factor. Mol Reprod Dev. 2002; 63(4):430-436, doi: 10.1002/mrd.10200, indexed in Pubmed: 12412044.

15. Concu M, Banzola I, Farina A, et al. Rapid clearance of mRNA for PLAC1 gene in maternal blood after delivery. Fetal Diagn Ther. 2005; 20(1): 27-30, doi: 10.1159/000081365, indexed in Pubmed: 15608456.

16. Massabbal E, Parveen $\mathrm{S}$, Weisoly $\mathrm{DL}$, et al. PLAC1 expression increases during trophoblast differentiation: evidence for regulatory interactions with the fibroblast growth factor-7 (FGF-7) axis. Mol Reprod Dev. 2005; 71(3): 299-304, doi: 10.1002/mrd.20272, indexed in Pubmed: 15803460.

17. Silva WA, Gnjatic S, Ritter E, et al. PLAC1, a trophoblast-specific cell surface protein, is expressed in a range of human tumors and elicits spontaneous antibody responses. Cancer Immun. 2007; 7: 18, indexed in Pubmed: 17983203.

18. Fant M, Barerra-Saldana H, Dubinsky W, et al. The PLAC1 protein localizes to membranous compartments in the apical region of the syncytiotrophoblast. Mol Reprod Dev. 2007; 74(7): 922-929, doi: 10.1002/mrd.20673, indexed in Pubmed: 17186554

19. Lau TW, Leung TN, Chan LYS, et al. Fetal DNA clearance from maternal plasma is impaired in preeclampsia. Clin Chem. 2002; 48(12): 2141-2146, indexed in Pubmed: 12446469.

20. Purwosunu $Y$, Sekizawa A, Okazaki S, et al. Prediction of preeclampsia by analysis of cell-free messenger RNA in maternal plasma. Am J Obstet Gynecol. 2009; 200(4): 386.e1-386.e7, doi: 10.1016/j.ajog.2008.11.035, indexed in Pubmed: 19217595.

21. Purwosunu $Y$, Sekizawa A, Farina A, et al. Cell-free mRNA concentrations of $\mathrm{CRH}, \mathrm{PLAC1}$, and selectin-P are increased in the plasma of pregnant women with preeclampsia. Prenat Diagn. 2007; 27(8): 772-777, doi: 10.1002/pd.1780, indexed in Pubmed: 17554801.

22. Farina A, Rizzo N, Concu M, et al. Lower maternal PLAC1 mRNA in pregnancies complicated with vaginal bleeding (threatened abortion $<20$ weeks) and a surviving fetus. Clin Chem. 2005; 51(1): 224-227, doi: 10.1373/clinchem.2004.041228, indexed in Pubmed: 15516331.

23. Ng EKO, Tsui NBY, Lau TK, et al. mRNA of placental origin is readily detectable in maternal plasma. Proc Natl Acad Sci U S A. 2003; 100(8): 47484753, doi: 10.1073/pnas.0637450100, indexed in Pubmed: 12644709.

24. DiFederico E, Genbacev O, Fisher SJ. Preeclampsia is associated with widespread apoptosis of placental cytotrophoblasts within the 
uterine wall. Am J Pathol. 1999; 155(1): 293-301, doi: 10.1016/S00029440(10)65123-1, indexed in Pubmed: 10393861.

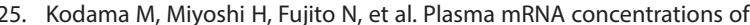
placenta-specific 1 (PLAC1) and pregnancy associated plasma protein A (PAPP-A) are higher in early-onset than late-onset pre-eclampsia. J Obstet Gynaecol Res. 2011; 37(4): 313-318, doi: 10.1111/j.1447-0756.2010.01349.x, indexed in Pubmed: 21392164.

26. Zanello M, Sekizawa A, Purwosunu $Y$, et al. Circulating mRNA for the PLAC1 gene as a second trimester marker (14-18 weeks' gestation) in the screening for late preeclampsia. Fetal Diagn Ther. 2014; 36(3): 196-201, doi: 10.1159/000360854, indexed in Pubmed: 25138310.

27. Fisher SJ. The placental problem: linking abnormal cytotrophoblast differentiation to the maternal symptoms of preeclampsia. Reprod Biol Endocrinol. 2004; 2: 53, doi: 10.1186/1477-7827-2-53, indexed in Pubmed: 15236649

28. Luttun A, Carmeliet P. Soluble VEGF receptor Flt1: the elusive preeclampsia factor discovered? J Clin Invest. 2003; 111(5): 600-602, doi: 10.1172/JCl18015, indexed in Pubmed: 12618513. 